\title{
REALITISASI PENDIDIKAN KARAKTER SEBAGAI WUJUD BUDAYA BELAJAR SISWA SEKOLAH DASAR
}

\author{
Oleh: \\ I Dewa Putu Sandat; I Nyoman Sueca \\ SDN 2 Tegallalang, Gianyar; Universitas Hindu Negeri I Gusti Bagus Sugriwa Denpasar \\ Sandatputu10@gmail.com; inyomansueca64@gmail.com
}

\begin{abstract}
The activities that the teacher does are hard work, smart work, and sincere work, and discipline must be used as guidelines in character education in schools. This is very important, especially to achieve optimal results, so that students as the young generation have the expected high characteristics which is the hope of the Indonesian government. This is done is to prevent public concern over the loss of identity / character in students. With a high character so that it will bring moral learners rooted in philosophy, experience and have cultural and religious values of the Indonesian nation. Thus character education must be continuous and never ending (never ending process), as an integrated part of preparing the nation's generation, which is adapted to the human figure having a future.

Character education must grow up the philosophy and practice of the whole character of this nation.. The character of the nation contains cultural that must be manifested in the cultural awareness and cultural intelligence of every citizen of the country.
\end{abstract}

Keywords: Character Education Success

\section{PENDAHULUAN}

Sebuah harapan Kemenristek dan Presiden Republik Indonesia yang menekankan konsep pada high standard, yang mencakup kerja keras, kerja cerdas, dan kerja iklas, serta disiplin harus dijadikan pedoman dalam pendidikan karakter di sekolah. Hal ini sangat penting, terutama untuk mencapai hasil yang optimal, sehingga peserta didik sebagai generasi muda (The Young Generation) memilki kerakter tinggi sesuai yang diharapkan. Kemenristek dan Presiden mencanangkan pendidikan karakter dan memasukannya dalam sebuah kurikulum sekolah, hal tersebut terjadi ketika masyarakat resah atas kondisi bangsa ini, yang seolaholah sudah kehilangan karakter.
Sedikitnya terdapat delapan jurus yang perlu diperhatikan dalam mensukseskan pendidikan karakter di sekolah. Kedelapan jurus tersebut adalah; (1) pahami hakikat pendidikan karakter, (2) sosialisasikan dengan tepat, (3) ciptakan lingkungan yang kondusif, (4) kembangkan serana dan sumber belajar yang memadai, (5) disiplinkan peserta didik), (6) pilih kepala sekolah yang cakap, (7) wujudkan guru yang dapat digugu dan ditiru, dan (8) libatkan seluruh warga sekolah dalam mensukseskan pendidikan karakter.

Pendidikan karakter harus berkelanjutana dan tak pernah berakhir (never ending process), sebagai bagian terpadu untuk menyiapkan genarasi bangsa, yang disesuaikan dengan sosok manusia masa depan, berakar pada filosofi, pengalaman dan 
GUNA WIDYA : JURNAL PENDIDIKAN HINDU

JURUSAN PENDIDIKAN AGAMA

FAKULTAS DHARMA ACARYA

UNIVERSITAS HINDU NEGERI I GUSTI BAGUS SUGRIWA DENPASAR
VOLUME 8 NOMOR 1 MARET 2021

ISSN : 2355-5696 (CETAK)

ISSN : 2655-0156 (ONLINE)

http://ejournal.ihdn.ac.id/index.php/GW nilai cultural, religius bangsa Indonesia. Pendidikan karakter harus menumbuhkembangkan filosofi dan pengamalan atas keseluruhan karakter bangsa ini secara utuh, dan menyeluruh (kaffah). Karakter bangsa mengandung perekat budaya dan cultural yang harus terwujud dalam kesadara cultural (cultural awareness) dan kecerdasan cultural (cultural intelligence) setiap warga Negara.

Pendidikan karakter memilki makna lebih tinggi dari pada pendidikan moral, karena pendidikan karakter tidak hanya berkaitan dengan masalah benar dan salah, tetapi bagaimana menanamkan kebiasaan (habituation) tentang hal-hal yang baik tentang kehidupan, sehingga peserta didik memiliki kesadran, kepekaan, dan pemahaman yang tinggi, serta kepedulian dan komitmen untuk menerapkan kebajikan dalam kehidupan sehari-hari. Dengan demikian dapat dikatakan bahwa orang berkarakter merupakan sifat alami seseorang dalam merespons situasi secara bermoral, yang diwujudkann dalam tindakan nyata melalui perilaku baik, jujur, ikhlas, bertanggung jawab, hormat terhadap orang lain dan nilainilai karakter mulia lainnya.

Mengingat sangat pentingnya dalam kehidupan bangsa, dan bernegara; Deng Xiaoping, sejak tahun 1985 telah melakukan reformasi pendidikan dengan memasukkan karakter dalam kurikulum formal, mulai dari jenjang prasekolahan hingga perguruan tinggu. Seseorang politisi Cina Li Lanqing (2005) dalam Mulyasa (2011) menyatakan pentingnya pendidikan karakter sebagai berikut, "throughout the reform of the education system, it is imperative to bear in mind that reform is for the fundamental purpose of turning every citizen into a man or woman of character and cultivating more constructive member of society" (sepanjang reformasi, system pendidikan sangat penting diingat bahwa reformasi adalah tujuan mendasar mengubah setiap warga negara menjadi pria atau wanita berkarakter dan menumbuhkan anggota masyarakat yang lebih mudah bangkit). Dampak dari upaya pendidikan karakter tersebut, cina mampu bangkit dari keterpurukan akibat dari revolusi kebudayaan Mao.

Harapan bahwa pendidikan karakter menekankan konsep pada high standard, yang mencakup kerja keras, kerja cerdas, dan kerja iklas, serta disiplin harus dijadikan pedoman dalam pendidikan karakter di sekolah dasar, untuk menjadikan peserta didik yang berkarakter tinggi sesuai yang diharapkan. Dengan berkarakter yang tinggi sehingga akan membawa peserta didik yang bermoral berakar pada filosofi, pengalaman dan memilki nilai cultural, religius bangsa Indonesia.

Kenyataanya bahwa pendidikan karakter sudah berjalan sejak lama di masingmasing sekolah namun belum menunjukkan hasil yang signifikan, sesuai yang diharapkan bangsa Indonesia. Dengan demikian sekolah tidak akan enti-entinya menerapkan pendidikan karakter untuk menjadikan bangsa yang memilki kehidupan masa depan.

\section{PEMBAHASAN}

Pada pembahasan ini, untuk mensukseskan pendidikan karakter dengan baik pada peserta didik di sekolah dasar, dapat dilakukan melalui;

\section{A. Pemahaman Hakikat Pendidikan Karakter.}

Memahami hakikat pendidikan karakter sangat penting, karena pendidikan karakter bergerak dari kesadaran (awarenes), pemahaman (understanding), kepedulian (concern), dan komitmen (commitmen), menuju tindakaan (acting). Oleh karena itu keberhasilan pendidikan karakter disekolahsekolah sangat bergantung pada ada atau 
GUNA WIDYA : JURNAL PENDIDIKAN HINDU

JURUSAN PENDIDIKAN AGAMA

FAKULTAS DHARMA ACARYA

UNIVERSITAS HINDU NEGERI I GUSTI BAGUS SUGRIWA DENPASAR
VOLUME 8 NOMOR 1 MARET 2021

ISSN : 2355-5696 (CETAK)

ISSN : 2655-0156 (ONLINE)

http://ejournal.ihdn.ac.id/index.php/GW tidaknya rasa kesadaran, pemahaman, kepedulian, dan komitmen dari semua warga sekolah terhadap peneyelenggaraan pendidikan karakter tersebut. Klipatrick (dalam Mulyasa, 2012: 14) mengemukakan bahwa salah satu penyebab ketidak mampuan seseorang berprilaku baik meskipun telah memiliki pemahaman tentang kebaikan itu (moral understanding) disebabkan karena tidak terlatih untuk melakukannya (moral doing). Oleh karena itu pendidikan karakter sebaiknya diajarkan melalui berbagai tindakan praktik dalam proses pembelajaran, jangan terlalu teoritis, dan jangan banyak membatasi aktivitas pembelajaran, apalagi hanya terbatas di dalam kelas.

Moral understanding sebagi aspek pertama yang harus diperhatikan dalam pendidikan karakter memiliki enam unsur, yaitu kesadaran moral (moral awareness), pengetahuan tentang nilai-nilai moral (knowing about moral values), penentuan sudut pandang (perspective taking), logika moral (moral reasoning), keberanian mengambil keputusan (decision making), dan pengenalan diri (self knowledge). Keenam unsur tersebut merupakan komponenkomponen yang harus ditekankan dalam pendidikan karakter, serta diajarkan kepada peserta didik dan diintegrasikan dalam seluruh pembelajaran secara kaffah (menyeluruh).

Moral loving/moral feeling merupakan penguatan aspek emosi peserta didik untuk menjadi manusia berkarakter. Penguatan ini berkaitan dengan bentukbentuk sikap yang harus dirasakan oleh peserta didik, yaitu kesadaran akan jati diri, percaya diri (self-esteem), motivasi diri (selfmotivation), disiplin diri (self-discipline), kepekaan terhadap penderitaan orang lain (emphaty), cinta kebenaran (loving the good), pengendalian diri (self-control), dan kerendahan hati (humility).
Jika kedua aspek diatas terwujud, maka moral acting sebagai outcome akan dengan mudah dilakuakn oleh peserta didik. Namun Megawangi (dalam Mulyasa, 2012: 15) mengemukakan bahwa karakter adalah tabiat yang langsung disetir oleh otak, oleh karena itu, ketiga tahapan tadi perlu disuguhkan kepada peserta didik melalui cara yang logis, rasional, dan demokratis, sehingga perilaku yang muncul benar-benar sebuah karakter yang diharapkan. Pendidikan karakter yang dilakukan oleh negara lain, seperti Amerika Serikat, Ingris, Jepang, dan Singapora telah sampai pada tahap tersebut, bahkan mereka telah menyiapkan lesson plan untuk setiap bentuk karakter yang telah dirumuskan mulai dari sekolah dasar sampai sekolah menengah.

Eloknya, untuk mensukseskan pendidikan karakter di sekolah-sekolah, perlu dilakukan identifikasi karakter, karena pendidikan karakter tanpa identifikasi karakter hanya akan menjadi sebuah perjalanan panjang tanpa ujung, seperti petualngan tanpa peta. Organisasi manapun di dunia ini yang menaruh perhatian besar terhadap pendidikan karakter selalu melakukan identifikasi karakter yang akan menjadi pilar perilaku individu. Dalam hal ini, Heritage Foundation (dalam Mulyasa, 2012: 15) merumuskan sembilan karakter dasar yang menjadi tujuan pendidikan karakter, kesembilan karakter tersebut adalah sebagai berikut;

1. Cinta kepada Tuhan dan alam semesta,

2. Tanggung jawab, disiplin dan mandiri,

3. Jujur,

4. Hormat dan santun,

5. Kasih saying, peduli, dan kerja sama,

6. Percaya diri, kreatif, kerja keras, dan pantang menyerah. 
GUNA WIDYA : JURNAL PENDIDIKAN HINDU

JURUSAN PENDIDIKAN AGAMA

FAKULTAS DHARMA ACARYA

UNIVERSITAS HINDU NEGERI I GUSTI BAGUS SUGRIWA DENPASAR
VOLUME 8 NOMOR 1 MARET 2021

ISSN : 2355-5696 (CETAK)

ISSN : 2655-0156 (ONLINE)

http://ejournal.ihdn.ac.id/index.php/GW
7. Keadilan dan kepemimpinan

8. Baik dan rendah hati

9. Toleransi , cinta damai dan persatuan.

Permasalahan yang muncul kemudian adalah diperlakukannya indikator-indikator dari setiap karakter sebagaimana dikemukakan diatas. Ini penting karena selama ini dalam praktik pembelajaran seharihari guru-guru masih berpegang teguh pada ranah pembelajaran hasil karya Bloom, dan kawan-kawan yang memang sampai saat ini teorinya belum terdandingi. Belum terdandingi teori tersebut, terutama karena kata-kata oprasionalnya yang mudah digunakan dan dipedomani oleh para guru dalam pembelajarn dan pengukurannya. Oleh karena itu agar pendidikan karakter itu bisa berhasil dalam memandu pribadi peserta didik perlu dirumuskan dan diidentifikasi kata-kata oprasional berkarakter yang dapat dijadikan pedoman para guru dalam pemeblajaran di sekolah. Hal ini juga yang mengemuka di kalangan para pendidik, baik di lingkukan formal maupun di lingkungan non formal, ketika berdiskusi dengan mereka tentang pendidikan karakter. Dengan kata lain, adanya kata-kata oprasional berkarakter akan sangat membatu para guru dalam merencanakan, melaksanakan, dan menilai keberhasilan pendidiakan karakter di sekolah, meskipun sebenarnya bisa dirumuskan oleh para guru dalam forum musyawarah guru (MGMP) atau Kelompok Kerja Guru (KKG).

Berkaitan dengan pendidikan karakter ini, Charakter Education Ouality Standars merekomendasikan 11 prinsip untuk mewujudkan pendidikan karakter yang efektif, sebagai berikut.

1. Mempromosi nilai-nilai dasar etika sebagai basis karakter.

2. Mengidentifikasi karakter secara komprehensif supaya mencakup pemikiran, perasaan dan perilaku.
3. Menggunakan pendekatan yang tajam, produktif dan efektif untuk membangun karakter.

4. Menciptakan komunitas sekolah yang memiliki kepedulian.

5. Memberikan kemampuan kepada peserta didik untuk menunjukkan perilaku yang baik.

6. Memilki cakupan terhadaqp kurikulum yang bermakna dan menantang yang menghargai semua peserta didik, membangun karakter mereka, dan membantu mereka untuk sukses.

7. Mengusahakan tumbuhnya motivasi diri dari para peserta didik.

8. Memfungsikan seluruh setaf sekolah sebagai komunitas moral yang berbagi tanggung jawab untuk pendidikan karakter dan setia kepada nilai dasar yang sama

9. Adanya pembagian kepemimpinan moral dan dukungan luas dalam membangun inisiatif pendidikan karakter.

10. Memfungsikan keluarga dan anggota masyarkat sebagai mitra dalamusaha utuk membangun karakter.

11. Mengevaluasi karakter sekolah, fungsi staf sekolah sebagai guruguru karakter dalam kehidupan peserta didik.

\section{B. Sosialisasikan Dengan Tepat.}

Dalam mensukseskan pendidikan karakter di sekolah dadalah mensosialisikan dengan tepat terhadap seluruh warga sekolah, bahkan masyarakat dan oranr tua peserta didik. Sosialisasi itu penting, agar seluruhwarga sekolah mengenal dan memahami visi dan misi sekolah, serta pendidikan karakter yang akan diimplementasikan.sosialisasi bisa dilakukan 
GUNA WIDYA : JURNAL PENDIDIKAN HINDU

JURUSAN PENDIDIKAN AGAMA

FAKULTAS DHARMA ACARYA

UNIVERSITAS HINDU NEGERI I GUSTI BAGUS SUGRIWA DENPASAR
VOLUME 8 NOMOR 1 MARET 2021

ISSN : 2355-5696 (CETAK)

ISSN : 2655-0156 (ONLINE)

http://ejournal.ihdn.ac.id/index.php/GW oleh kepala sekolah apabila yang bersangkutan sudah mengenal dan cukup memahaminya. Namun jika kepala sekolah belum memahami, atau masih belum mantap dengan konsep-konsep pendidikan karakter yang akandilakukan maka bisa mengundang ahlinya yang ada dimasyarakat, baik dari kalangan pemerintah, akademisi, maupun dari kalangan penulis.

Sosialisasi perlu dilakukan secara matang kepada berbagai pihak agar pendidikan karakter yang ditawarkan dapat dipahami dan diterapkan secara optimal, karena sosialisasi merupakan lamngkah penting yang akan menunjang dan menentukan keberhasilan keberhasilan pendidikan karakter. Setelah sosialisasi, kemudian diadakan musyawarah antara kepala sekolah, guru, tenaga pendidik, dan komite sekolah untuk mendapatkan persetujuan dan pengesahan dari berbagai pihak, dalam rangka mensukseskan implementasi pendidikan karakter.

\section{Ciptakan Lingkungan yang Kondusif}

Lingkungan yang kondusif-akademik, baik secara fisik maupun nonfisik dapat mensukseskan keberhasilan pendidikan karakter disekolah. Lingkungan sekolah yang aman, nyaman dan tertib, dipadukan dengan optimisme dan harapan yang tinggi dari seluruh warga sekolah, kesehatan sekolah. serta kegiatan-kegiatan yang terpusat pada peserta didik (student-centered activities) merupakan iklim yang dapat membangkitkan nafsu, gairah, dan semangat belajar. Iklim yang demikian akan mendorong terciptanya masyarakat belajar di sekolah, karena iklim belajar yang kondusif merupakan tulang punggung dan faktor pendorong yang dapat memberikan daya tarik tersendiri bagi proses belajar, sebaliknya iklim belajar yang kurang menyenangkan akan menimbulkan kejenuhan dan rasa bosan.
Lingkungan masyarakat, para pemimpin, pembuat kebijakan, pemegang otoritas di masyarakat, orang tua harus menjadi role model yang baik dalam menanamkan karakter yang baik kepada anaknya. Berbagai perilaku ambigu dan inkonsistensi (tidak taat) yang diperlihatkan masyarakat, baik langsung maupun tidak langsung akan memberi kontribusi yang buruk yang secara signifikan dapat melemahkan karakter peserta didik.

Lingkungan yang kondusif harus ditunjang oleh berbagai fasilitas belajar yang menyenangkan; seperti sarana. laboratorium, pengaturan lingkungan, penampilan dan sikap guru, hubungan yang harmonis antara peserta didik dengan guru dan di antara para peserta didik itu sendiri, serta penataan organisasi dan bahan pembelajaran secara tepat. Sesuai dengan kemampuan dan perkembangan peserta didik. lklim belajar yang menyenangkan akan membangkitkan semangat dan menumbuhkan aktivitas serta kreativitas peserta didik. Dalam hal ini dapat dikemukakan suatu dalil bahwa semakin menyenangkan tatanan lingkungan fisik, akan memberikan dampak positif bagi proses belajar. Para pakar psikologis aliran ekologik telah mendapalkan temuan-temuan penelitian bahwa tata.

Lingkungan yang kondusif antara lain dapat dikembangkan melalui berbagai layanan dan kegiatan sebagai berikut.

1. Memberikan pilihan bagi peserta didik yang lambat maupun yang cepat dalam melakukan tugas pembelajaram.

2. Memberikan pembelajaran remedial bagi para peserta didik yang kurang berprestasi, atau berprestasi rendah.

3. Mengembangkan organisasi kelas yang efektif, menarik, nyaman, dan 
GUNA WIDYA : JURNAL PENDIDIKAN HINDU

JURUSAN PENDIDIKAN AGAMA

FAKULTAS DHARMA ACARYA

UNIVERSITAS HINDU NEGERI I GUSTI BAGUS SUGRIWA DENPASAR
VOLUME 8 NOMOR 1 MARET 2021

ISSN : 2355-5696 (CETAK)

ISSN : 2655-0156 (ONLINE)

http://ejournal.ihdn.ac.id/index.php/GW aman bagi perkembangan potensi seluruh peserta didik secara optimal.

4. Menciptakan kerja sama saling menghargai. baik antarpeserta didik maupun antara peserta didik dengan guru dan pengelola pembelajaran lain.

5. Melibatkan peserta didik dalam proses perencanaan belajar dan pembelajaran. Dalam hal ini, guru harus mampu memposisikan diri sebagai pembimbing dan manusia sumber.

\section{Dukung dengan Fasilitas dan Sumber Belajar yang Memadai}

Fasilitas dan sumber belajar yang perlu dikembangkan dalam mendukung suksesnya implementasi pendidikan karakter antara lain laboratorium, pusat sumber belajar, dan perpustakaan, serta tenaga pengelola dan peningkatan kemampuan pengelolaannya. Fasilitas dan sumber belajar tersebut perlu didayagunakan seoptimal mungkin, dipelihara, dan disimpan dengan sebaik-baiknya. Selain itu, kreativitas guru dan peserta didik perlu senantiasa ditingkatkan untuk membuat dan mengembangkan alat-alat pembelajaran serta alat peraga lain yang berguna bagi peningkatan kualitas pembelajaran. Kreativitas tersebut diperlukan, bukan semata-mata karena keterbatasan fasilitas dan dana dari pemerintah, tetapi merupakan kewajiban yang harus melekat pada setiap guru untuk berkreasi, berimprovisasi, berinisiatif dan inovatif.

Dalam pengembangan fasilitas dan sumber belajar, selain guru harus mampu membuat sendiri alat pembelajaran dan alal peraga, juga harus berinisiatif mendayagunakan lingkungan sekolah sebagai sumber belajar yang lebih konkret. Pendayagunaan lingkungan sebagai sumber belajar, misalnya memanfaatkan batu-batuan, tanah, tumbuh-tumbuhan, keadaan alam, pasar, kondisi social, ekonomi, dan budaya kehidupan yang berkembang di masyarakat. Untuk kepentingan tersebut, perlu senantiasa diupayakan peningkatan pengetahuan guru dan didorong terus untuk menjadi guru yang kreatif dan profesional, terutama dalam pengadaan serta pendayagunaan fasilitas dan sumber belajar secara luas.

Pendayagunaaan fasilitas dan sumber belajar perlu dikaitkan dengan kompetensi dasar yang ingin dicapai dalam proses pembelajaran. Dengan kata lain, fasilitas dan sumber belajar dipilih dan digunakan dalam proses belajar apabila sesuai dan menunjang tercapainya kompetensi dasar. Dalam menyukseskan implementasi pendidikan karakter, pendayagunaan fasilitas dan sumber belajar memiliki kegunaan sebagai berikut.

1. Merupakan pembuka jalan dan pengembangan wawasan terhadap proses pembelajaran yang akan ditempuh.

2. Merupakan pemandu secara teknis dan langkah-langkah operasional untuk menelusuri secara lebih telili menuju pada pembentukan kompetensi secara tuntas.

3. Memberikan berbagai macam ilustrasi dan contoh-contoh yang berkaitan dengan kompetensi dasar yang akan dikembangkan.

4. Memberikan petunjuk dan gambaran kaitan kompetensi dasar yang sedang dikembangkan dengan kompetensi dasar lainnya.

5. Menginformasikan sejumlah penemuan baru yang pernah diperoleh orang lain yang berhubungan dengan mata pelajaran tertentu.

Pengembangan fasilitas dan sumber belajar sudah sewajarnya dilakukan oleh sekolah, mulai dari pengadaan, pemeliharaan

Realitisasi Pendidikan Karakter Sebagai Wujud Budaya Belajar Siswa Sekolah Dasar SDN 2 Tegallalang, Gianyar; Universitas Hindu Negeri I I I Dewa Putu Sandat; I Nyoman Sueca Gusti Bagus Sugriwa Denpasar 
GUNA WIDYA : JURNAL PENDIDIKAN HINDU

JURUSAN PENDIDIKAN AGAMA

FAKULTAS DHARMA ACARYA

UNIVERSITAS HINDU NEGERI I GUSTI BAGUS SUGRIWA DENPASAR
VOLUME 8 NOMOR 1 MARET 2021

ISSN : 2355-5696 (CETAK)

ISSN : 2655-0156 (ONLINE)

http://ejournal.ihdn.ac.id/index.php/GW dan perbaikan. Hal ini didasari oleh kenyataan bahwa sekolahlah yang paling mengetahui kebutuhan fasilitas dan sumber belajar, baik kecukupan, kesesuaian, maupun kemutakhirannya, terutama sumber-sumber belajar yang dirancang (by design) secara khusus untuk kepentingan pembelajaran.

\section{E. Tumbuhkan Disiplin Peserta Didik}

Disiplin diri peserta didik bertujuan untuk membantu menemukan diri, mengatasi, dan mencegah timbulnya problem-problem disiplin, serta berusaha menciptakan suasana yang aman. Nyaman, dan menyenangkan bagi kegiatan pembelajaran, sehingga mereka menaati segala peraturan yang ditetapkan.

Dalam rangka menyukseskan pendidikan karakter, guru harus mampu menumbuhkan disiplin peserta didik, terutama disiplin diri (self discipline).

Guru harus mampu membantu peserta didik mengembangkan pola perilakunya. meningkatkan standar perilakunya, dan melaksanakan aturan sebagai alat untuk menegakan disiplin. Untuk mendisiplinkan peserta didik perlu dimulai dengan prinsip yang sesuai dengan tujuan pendidikan nasional., yakni sikap demokratis sehingga peraturan disiplin perlu berpedoman pada hal tersebut, yakni dari, oleh dan untuk peserta didik, sedangkan guru tut wuri handayani. Soelaeman (dalam Mulyasa, 2012: 26) mengemukakan bahwa guru berfungsi sebagai pengemban ketertiban, yang patut digugu dan ditiru, tapi tidak diharapkan sikap yang otoriter.

Memperhatikan pendapat Reisman and Payne (1987:239-241), dapat dikemukakan sembilan strategi untuk mendisiplinkan peserta didik, sebagai berikut.

1. Konsep diri (self-concept), strategi ini menekankan bahwa konsep-konsep diri masing-masing individu merupakan faktor penting dari setiap perilaku.

2. Keterampilan berkomunikasi (communication Skills), guru harus memiliki keterampilan komunikasi yang efektif agar mampu menerima semua perasaan, dan mendorong timbulnya kepatuhan peserta didik.

3. Konsekuensi-konsekuensi logis dan alami (natural and logical consequences), perilaku-perilaku yang salah terjadi karena peserta didik telah mengembangkan kepercayaan yang salah terhadap dirinya.

4. Klarifikasi nilai (values clarification), strategi ini dilakukan untuk membantu peserta didik dalam menjawab pertanyaannya sendiri tentang nilainilai dan membetuk sistem nilainya sendiri.

5. Analisis transaksional (transactional analysis). disarankan agar guru belajar sebagai orang dewasa terutama apabila berhadapan dengan peserta didik yang menghadapi masalah.

6. Terapi realitas (reality theraphy), sekolah harus berupaya mengurangi kegagalan dan meningkatkan keterlibatan. Dalam hal ini guru harus bersikap positif dan bertanggung jawab.

7. Disiplin yang terintegrasi (assertive discipline), metode ini menekankan pengendalian penuh oleh guru untuk mengembangkan dan mempertahankan peraturan.

8. Modifikasi perilaku (behavior modification) perilaku salah disebabkan oleh lingkungan sebagai tindakan remediasi. Sehubungan dengan hal tersebul, dalam 
GUNA WIDYA : JURNAL PENDIDIKAN HINDU

JURUSAN PENDIDIKAN AGAMA

FAKULTAS DHARMA ACARYA

UNIVERSITAS HINDU NEGERI I GUSTI BAGUS SUGRIWA DENPASAR
VOLUME 8 NOMOR 1 MARET 2021

ISSN : 2355-5696 (CETAK)

ISSN : 2655-0156 (ONLINE)

http://ejournal.ihdn.ac.id/index.php/GW pembelajaran perlu diciptakan lingkungan yang kondusif.

9. Tantangan bagi disiplin (dare to discipline), guru diharapkan cekatan, sangat terorganisasi, dan dalam pengendalian yang tegas. Pendekatan ini mengasumsikan bahwa peserta didik akan menghadapi berbagai keterbalasan pada hari-hari pertama di sekolah, dan guru perlu membiarkan mereka untuk mengetahui siapa yang berada dalam posisi sebagai pemimpin Membina disiplin peserta didik dengan Sembilan strategi tersebut, harus memperlimbangkan berbagai situasi. dan memahami faktor-faktor yang mempengaruhinya.

\section{F. Pilih Kepala Sekolah yang Cakap}

Kepala sekolah yang cakap merupakan salah satu faktor yang dapat mendorong sekolah dalam mewujudkan visi, misi. (ujuan, dan sasaran sekolah melalui program-program yang dilaksanakan secara terencana dan bertahap. Oleh karena itu, dalam menyukseskan pendidikan karakter di sekolah perlu dipilih kepala sekolah yang cakap, terampil dengan kemampuan manajemen serta kepemimpinan yang tangguh, agar mampu mengambil keputusan dan prakarsa untuk meningkatkan mutu sekolah. Kepala sekolah yang cakap diperlukan, terutama untuk memobilisasi sumber daya sekolah dalam kaitannya dengan perencanaan dan evaluasi program sekolah, sarana dan sumber belajar, pelayanan peserta didik, hubungan sekolah dengan masyarakat, penciptaan iklim sekolah, dan lebih khusus lagi berkaitan dengan manajemen keuangan.

Dalam menyukseskan pendidikan karakter, perlu dipersiapkan kepala sekolah yang cakap melalui pengangkatan yang profesional: misalnya dipilih dalam kurun waktu tertentu (3-5 tahun), dan setelah itu dilakukan lagi pemilihan yang baru. Hal ini akan menumbuhkan iklim demokratis di sekolah. yang akan mendorong terciptanya iklim yang kondusif bagi terciptanya kualitas pembelajaran yang optimal untuk mengembangkan seluruh potensi peserta didik.

Kepala sekolah yang cakap dan dan professional harus berusaha menanamkan, memajukan dan meningkatkan sedikitnya empat macam nilai, yakni pembinaan mental, moral, fisik, dan artistik. Pembinaan dilakukan sebagai berikut;

1. Pembinaan mental yaitu membina para tenaga kependidikan tentang halhal yang berkaitan dengan sikap batin dan watak. Dalam hal ini, kepala sekolah harus mampu menciptakan iklimyang kondusif agar setiap tenaga kependidikan dapat melaksanakan tugas dengan baik, secara proporsional dan profesional.

2. Pembinaan moral, yaitu membina para tenaga kependidikan tentang hal-hal yang berkaitan dengan ajaran baik buruk mengenai suatu perbuatan, sikap dan kewajiban sesuai dengan tugas masing-masing tenaga kependidikan.

3. Pembinaan fisik, yaitu membina para tenaga kependidikan tentang hal-hal yang berkaitan dengan kondisi jasmani atau badan, kesehatan dan penampilan mereka secara lahiriah. Kepala sekolah harus mampu memberikan dorongan agar para tenaga kependidikan terlibat secara aktif dan kreatif dalam berbagai kegiatan.

4. Pembinaan artistik, yaitu membina tenaga kepndidikan. Dalam hal ini, kepala sekolah dibantu oleh para pembantunya harus mampu

Realitisasi Pendidikan Karakter Sebagai Wujud Budaya Belajar Siswa Sekolah Dasar SDN 2 Tegallalang, Gianyar; Universitas Hindu Negeri I | I Dewa Putu Sandat; I Nyoman Sueca Gusti Bagus Sugriwa Denpasar 
GUNA WIDYA : JURNAL PENDIDIKAN HINDU

JURUSAN PENDIDIKAN AGAMA

FAKULTAS DHARMA ACARYA

UNIVERSITAS HINDU NEGERI I GUSTI BAGUS SUGRIWA DENPASAR
VOLUME 8 NOMOR 1 MARET 2021

ISSN : 2355-5696 (CETAK)

ISSN : 2655-0156 (ONLINE)

http://ejournal.ihdn.ac.id/index.php/GW merencanakan

pembinaan

karyawisata,

berbagai

program

artistik

seperti

pelaksanaannya tidak mengganggu

kegiatan pembelajaran.

\section{G. Wujudkan Guru yang Dapat Digugu dan Ditiru}

jujur, suka menolong dikatakan sebagai orang yang berkarakter mulia. Pendidikan karakter akan menumbuhkan kecerdasan emosi peserta didik yang meliputi kemampuan mengembangkan potensi diri dan melakukan hubungan sosial dengan manusia lain. Karakter yang baik dan berkualitas perlu dibentuk dan dibina sejak dini. dan ditindaklanjuti di bangku sekolah; karenanya. sebuah sistem pendidikan yang efeklif harus mampu membentuk manusia manusia berkarakler yang sangat diperlukan dalam mewujudkan sebuah negara dan bangsa yang bermartabat. Hal ini sejalan dengan ungkapan Socrates: "Then the man who's going 10 be a fine and good guardian of the city for us will in nature be philosophic, spirited, swift.and strong" (Bloom, A.: 1901).

Untuk menyukseskan implememasi pendidikan karakter di sekolah perlu mengubah paradigma guru, sesuai dengan kebutuhan dan perkembangan zaman. Tugas guru tidak hanya menyampaikan informasi kepada peserta didik, tetapi harus dilatih menjadi fasilitator yang bertugas memberikan kemudahan belajar (facilitate of learning) kepada seluruh peserta didik, agar mereka dapat belajar dalam suasana yang menyenangkan. Gembira, penuh semangat, tidak cemas, dan berani mengemukakan pendapat secara terbuka. Rasa gembira, penuh semangat. tidak cemas. dan berani mengemukakan pendapat secara terbuka merupakan modal dasar bagi peserta didik untuk tumbuh dan berkembang menjadi manusia yang siap beradaptasi, menghadapi berbagai kemungkinan, dan memasuki era globalisasi yang penuh berbagai tantangan.

\section{PENUTUP}

Keberhasilan pendidikan karaktr terletap pada konsep high standard, yang mencakup kerja keras, kerja cerdas, dan kerja iklas, serta disiplin harus dijadikan pedoman dalam pendidikan karakter di sekolah. Hal ini sangat penting, terutama untuk mencapai hasil yang optimal, sehingga peserta didik sebagai generasi muda (The Young Generation) memilki kerakter tinggi sesuai yang diharapka

Pendidikan karakter memilki makna lebih tinggi dari pada pendidikan moral, karena pendidikan karakter tidak hanya berkaitan dengan masalah benar dan salah, tetapi bagaimana menanamkan kebiasaan (habituation) tentang hal-hal yang baik tentang kehidupan, sehingga peserta didik memiliki kesadran, kepekaan, dan pemahaman yang tinggi, serta kepedulian dan komitmen untuk menerapkan kebajikan dalam kehidupan sehari-hari. Dengan demikian dapat dikatakan bahwa orang berkarakter merupakan sifat alami seseorang dalam merespons situasi secara bermoral, yang diwujudkann dalam tindakan nyata melalui perilaku baik, jujur, ikhlas, bertanggung jawab, hormat terhadap orang lain dan nilainilai karakter mulia lainnya.

Untuk mensukseskan pendidikan karakter di sekolah dapat dilakukan melalui; pahami hakekat pendidikan karakter, mensosialisasikan dengan tepat, ciptakan lingkungan yang kondusip, dukungan dengan fasilitas dan sumber belajar yang memadai, tumbuhkan disipli peserta didik, pilih kepala seklah yang cakap, dan wujudkan guru yang dapat digugu dan ditiru.

\section{DAFTAR PUSTAKA}

Depdiknas, $\begin{array}{ccc}2000 . & \text { Keputusan Mentri } \\ & \text { Pendidikan Nasional No. }\end{array}$


GUNA WIDYA : JURNAL PENDIDIKAN HINDU JURUSAN PENDIDIKAN AGAMA FAKULTAS DHARMA ACARYA

UNIVERSITAS HINDU NEGERI I GUSTI BAGUS SUGRIWA DENPASAR
010/0/2000 tentang Organisasi dan Tata Kerja Departemen Pendidikan Nasional. Jakarta: Depdiknas.

Jalal,Supriadi, 2001. Reformasi Pendidikan dalam Konteks Otonomi Daerah. Yogyakarta: Adi Cita.

Kemdiknas. 2010. Desain Induk Pendidikan Karakter. Jakarta.

Kemko Kesra RI 2010. Kebijakan Nasional Pembangunan Karakter Bangsa. Jakarta.

Koellhoffer, Tara Tomczyk. 2009. Charakter Education Being Fair and Honest. Now York: Infobase Publishing.

Koesoema A. Doni. 2007. Pendidikan Karakter Strategi Mendidk Anak di Zaman Global. Jakarta: Gramedia Widiasarana Indonesia.

Kementerian Pendidikan Nasional. 2010. Pembangunan Pendidikan Budaya dan Karakter Bangsa
VOLUME 8 NOMOR 1 MARET 2021

ISSN : 2355-5696 (CETAK)

ISSN : 2655-0156 (ONLINE)

http://ejournal.ihdn.ac.id/index.php/GW
Pedoman Sekolah. Jakarta: Puskur Balitbang Kemdiknas.

Koentjaraningrat. 1981. Pengantar Ilmu Antropologi. Jakarta: Rineka Cipta.

Mattulada . 1990. Desentralisasi pendidikan dalam Pelaksanaan Manajemen Pembangunan. Jakarta: Pustaka Sinar Harapan.

Mengawangi, Ratna. 2004. Pendidikan Karakter Solusi yang Tepat Untuk Membangun Bangsa. Jakarta; BP Migas dan Star Energy.

Mulyasa, E. 2002. Kurikulum Berbasis kompetensi.

Konsep Karakteritik dan Implementasi. Bandung: Remaja Rosdakarya. . 2012. Manajemen Pendidikan Karakter. Jakarta: Bumi Aksara. 